\title{
Displacement pattern of the Sinai area: first results from GPS
}

\author{
Federica Riguzzi $\left({ }^{1}\right)$, Salah M. Mahmoud $\left({ }^{2}\right)$ and Ali Tealeb $\left({ }^{2}\right)$ \\ ${ }^{1}$ ) Istituto Nazionale di Geofisica, Roma, Italy \\ $\left.{ }^{2}\right)$ National Research Institute of Astronomy and Geophysics (NRIAG), Helwan, Cairo, Egypt
}

\begin{abstract}
A network of 12 GPS stations, seven of them located on the Sinai peninsula, another four on the west shore of the Gulf of Suez and the last on the inner Gulf of Aqaba (ELAT, Israel) was analyzed twice, processing GPS data recorded in November 1997 and in May 1998. A rigorous statistical analysis based on the $F$ (Fisher) test applied on the detected coordinate differences showed significant displacement at all the sites located on the Sinai peninsula with respect to the others. The planar displacements of the Sinai sites are of the order of $1.5 \mathrm{~cm}$ in the considered time span. The agreement exhibited by the Sinai displacements, both in magnitude and azimuth, taking into with respect to the Africaters, provides evidence that the Sinai peninsula behaves like a rigid block or sub-plate Although it is not possible to the lack of GPS possible to draw exhaustive conclusions on the geodynamics of the Suez and Sinai areas and lateral motion of the Aqaba-Levant fault. Morsula makes the analysis incomplete, our results agree well with the left rather unexpectedly, a contraction component
\end{abstract}

Key words Sinai - Gulf of Suez - Aqaba-Levant fault-GPS-displacements

\section{Introduction}

The aim of this paper is to shed light on the kinematics of the Sinai area by estimating the displacements and velocities of a GPS network composed of 11 sites located on the northeastern corner of the African plate, from the Gulf of Suez to the Sinai peninsula.

From a geophysical point of view, this area is very interesting because its tectonics is dominated by the active boundary between the Afri-

Mailing address: Dr. Federica Riguzzi, Istituto Nazionale di Geofisica, Via di Vigna Murata 605, 00143 Roma, Italy; e-mail: riguzzi@ing750.ingrm.it can and Arabian plates producing large deformations and high seismic activity.

Many geological and seismological investigations have been undertaken in this area since the beginning of this century, reaching a rapid increase with the growth in petroleum research, so that now it is usually accepted that the Sinai peninsula is a sub-plate of the African plate (Ben-Menahem et al., 1976).

At present, geological and tectonic evidence lead us to consider the Sinai peninsula moving southwestward with respect to Arabia along the Aqaba-Levant fault system at a mean rate of about $8-9 \mathrm{~mm} / \mathrm{yr}$, while the Gulf of Suez is considered to have minor extensional motion (perhaps $<1 \mathrm{~mm} / \mathrm{yr}$ ) with lower seismic activity than the Aqaba area (Le Pichon and Gaulier, 1988; Steckler et al., 1988).

Seismic activity mainly occurs along the borders of the Sinai peninsula, in the Gulf of 
Suez (mainly in its southern part), along the Aqaba-Levant fault system, where it reaches the highest level; on the contrary, the intraplate seismicity is widespread and low.

The presence in the Gulf of Suez area of seismic activity with extensional features seems to contradict the previous conclusions, so that the real kinematics of the Sinai triple junction and related areas is still a not entirely understood question.

Recently, thanks to the development of the high precision positioning spatial techniques, a GPS network of 11 sites was established by NRIAG (Mahmoud et al., 1998), with the aim to study the geodynamic evolution of the Sinai area and to answer to the following questions:

1) What is the displacement rate of this area?

2) Is GPS able to confirm the sub-plate behaviour of the Sinai peninsula?

3) Are the detectable displacements mainly seismic or even aseismic?

This paper reports the rigorous analysis and comparison between two GPS campaigns made in 1997 and 1998 on the Sinai network. To strengthen our analysis we added data from the permanent tracking site of ELAT, so that the final GPS network is composed of 12 sites.

\section{Seismotectonic setting}

The tectonics of this area is mainly dominated by the separation of the Arabian from the African plate. During the Neogene, the northeastward motion of the Arabian peninsula produced the opening of the Red Sea with the characteristics of a new young basin with a thinning of lithosphere and presence of extensional tectonics. In the Oligocene-Miocene, the opening mainly involved the Red Sea and propagated along the Gulf of Suez area. The opening process produced uplift bordering rift and subsidence caused by the crustal thinning of lithosphere (Steckler, 1985). During the Late Miocene, the opening of the Suez area slowed and the Red Sea rift produced a NNE left shear motion with extensional component in the Aqaba-Levant area.
The triple junction among the Gulf of Suez rift, the Aqaba-Levant transform fault and the Red Sea rift is located south of the Sinai peninsula. The main tectonic features led the Sinai area to be considered a sub-plate which accommodates the main motion of the left-lateral transform fault of Aqaba with the low extensional motion of the Suez Gulf, in the framework of the Red Sea opening (fig. 1).

The question of whether the triggered motion of the Aqaba-Levant fault system has entirely or partially replaced the Gulf of Suez opening is still under debate.

Recent studies show that the oldest movements of the Aqaba-Dead Sea fault zone are younger than those in the Suez basin, thus suggesting the end of the extension of the Gulf of Suez and the transfer of the motion along the Aqaba-Levant fault zone about $10 \mathrm{Ma}$ ago. According to these studies, the Gulf of Suez shows, at present, very low rates of extensional feature ( $<1 \mathrm{~mm} / \mathrm{yr}$ ) and tectonic subsidence (Steckler et al., 1988); on the contrary, the Aqaba-Levant transform system displays a higher rate of motion with geological evidence suggesting an average value of about $8-9 \mathrm{~mm} / \mathrm{yr}$ (Le Pichon and Gaulier, 1988).

The present seismic activity is mainly concentrated along the three main fault systems reaching a maximum in the Aqaba-Levant area, where very long seismic series are associated with the greatest seismic events of the whole area (Salamon et al., 1996; Fattah et al., 1997).

Evidence of a still active extensional style in the Gulf of Suez is given by the focal mechanism solutions of the main seismic events which occurred in this area (Jackson et al., 1988). Figure 1 shows the focal mechanisms of events with $M \geq 5$ coming from the CMT (Centroid Moment Tensor) solutions provided by the Harvard CMT Catalog from 1977 to date (Dziewonski and Woodhouse, 1983 and subsequent papers in Phys. Earth Planet. Inter.) and the solutions given in Jackson et al. (1988). Focal mechanisms characterize the Gulf of Suez by extensional features and the Aqaba-Levant fault system by both left lateral strike slip and extensional styles. The largest earthquake occurred in November 22, 1995 in the Gulf of Aqaba with magnitude $M_{w}=7.2$. 


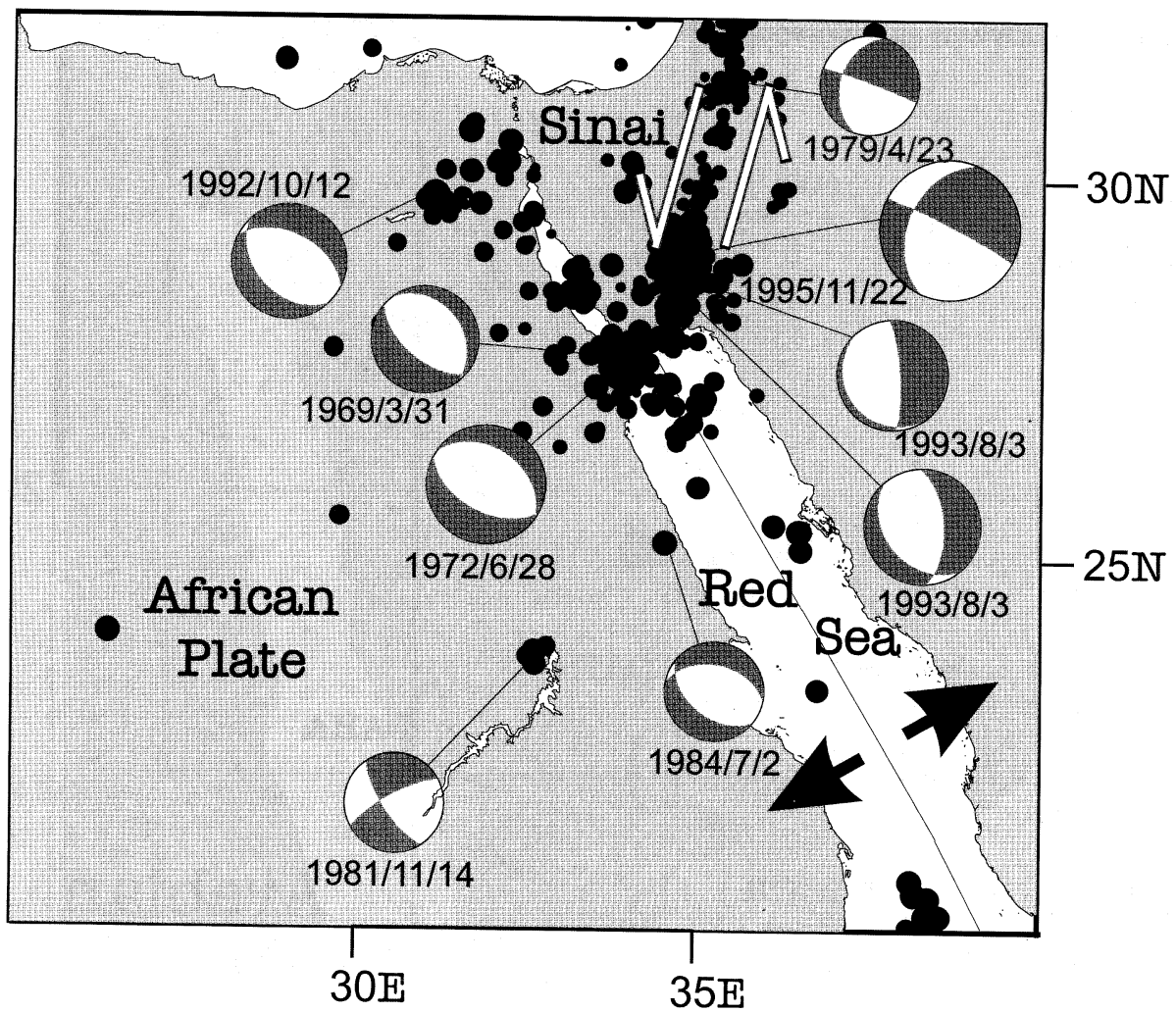

Fig. 1. Seismic activity with $M>3$ (I.S.C.) and focal mechanisms from the CMT Catalog (Dziewonski and Woodhouse, 1983 and subsequent papers in Phys. Earth Planet. Inter.) and the solutions given by Jackson et al. (1988), for events with $M \geq 5$ which occurred from 1969 to date. White arrows show the main motion component of the Aqaba-Levant fault system; black arrows display the Red Sea opening approximate direction.

\section{GPS campaigns and data analysis}

The network consists of 11 non-permanent GPS stations, seven located on the Sinai peninsula and the other four on the west shore of the Gulf of Suez (fig. 2). Thanks to the development of the worldwide permanent GPS tracking network within the IGS (International GPS Service) program, we included in the analysis data coming from ELAT (Israel), at present the closest IGS site to the Sinai network, located on the inner part of the Gulf of Aqaba.

Two GPS campaigns were carried out with dual frequency Trimble 4000SSE and 4000SSI receivers (Mahmoud et al., 1998). The first in
1997, from November 20 to December 2; the return campaign was performed in 1998, from May 25 to 31 . The observing session time span was $8 \mathrm{~h}$ with $30 \mathrm{~s}$ sampling rate. Not all the network sites were measured at the same time, the number of the receivers involved in the two campaigns being limited, so that the inclusion of ELAT in the analysis was crucial to improve the analysis itself.

Data analysis follows a well-tested procedure (Crespi and Riguzzi; 1998); it consists of GPS data processing, network adjustments and comparison between the two network solutions using a statistical analysis to evaluate the significance of the observed coordinate differences. 


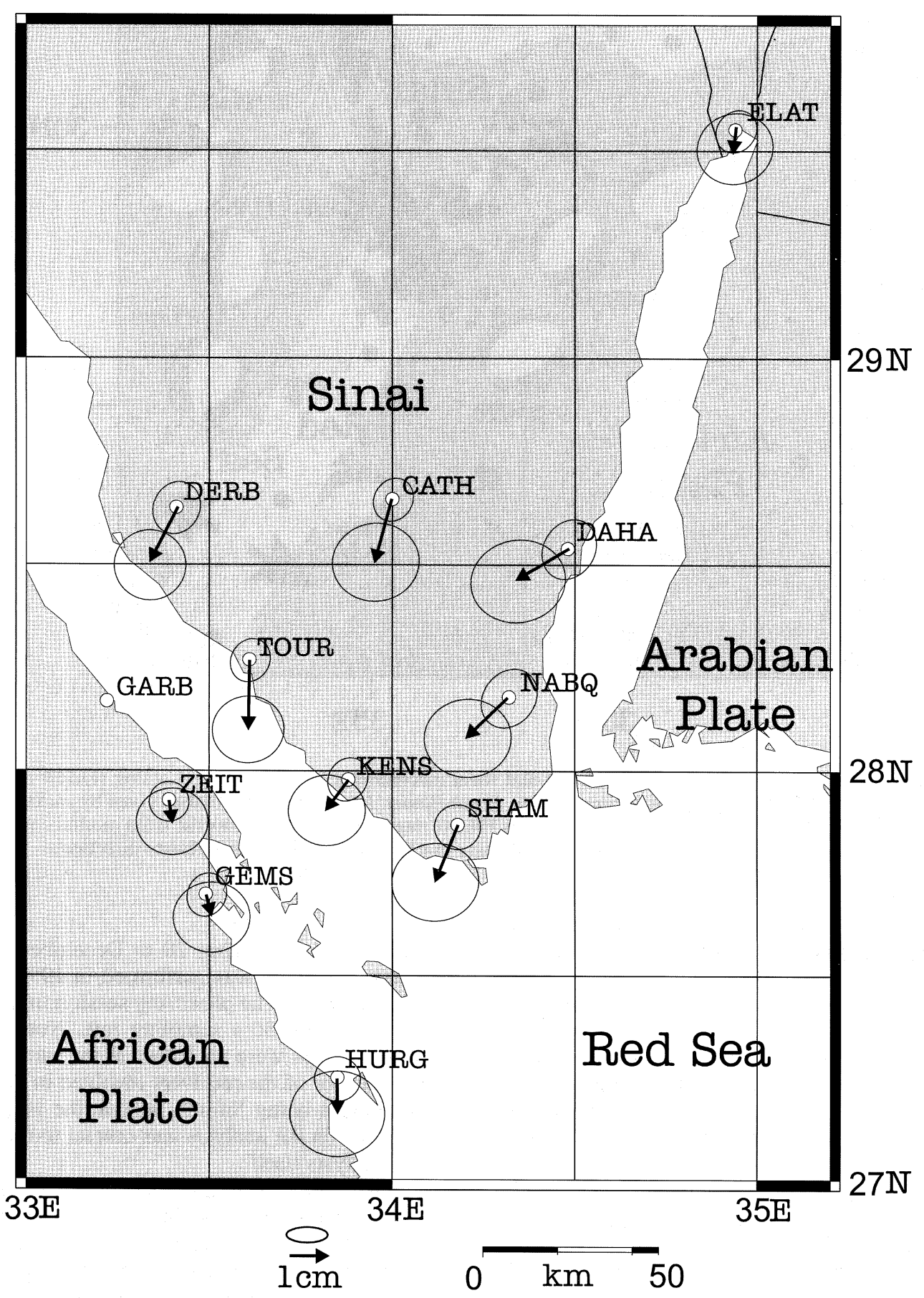

Fig. 2. 2D vector displacements and error ellipses at $95 \%$ confidence level computed with respect to GARB. 
In the end, the computation of the $2 \mathrm{D}$ vector displacements and the corresponding error ellipses on the local tangent plane was done.

GPS data processing was performed by the Bernese GPS software v. 4.0, developed at Bern University (Rothacher et al., 1996), following the manual suggestions given for mean size network (baselines are generally within $27-90 \mathrm{~km}$, a few of them linking ELAT exceed $130 \mathrm{~km}$ ). Precise ephemerides, satellite clock corrections, antenna height phase center variations and some other general files provided by CODE (Center of Orbit Determination in Europe) of Bern University were included in the computation. Relative tropospheric delay parameters every two hours were estimated starting from the Saastamoinen standard model.

To achieve good a priori coordinates, a preliminary complete run of the Bernese software was carried out to compute the network position with respect to the GPS permanent tracking sites of NOTO (Noto) and BAHA (Bahrain), whose coordinates and velocities are provided by the ITRF96 solution (Boucher, 1998).

Each observing session was processed separately. All the session solutions pertaining to each campaign were adjusted by NETGPS, a software suitably implemented to analyze GPS networks (Crespi, 1996).

Table I shows the precisions of the two adjustments (1997 and 1998) in terms of maximum and mean error ellipse semiaxes (computed on the local tangent plane) and the corresponding mean confidence interval on height, at 95\% confidence level. The planar error ellipse semiaxes range within $1.0 \mathrm{~cm}$, whilst the mean

Table I. Sinai network. Precision at $95 \%$ confidence level. $S_{\mathrm{MAX}}, S_{\mathrm{M}}$ are respectively the maximum and mean values of the error ellipse semiaxes; INT $h$ the corresponding confidence mean interval on height.

\begin{tabular}{|c|c|c|c|c|}
\hline \multicolumn{2}{|c|}{ Network } & \multirow{2}{*}{$\begin{array}{l}S_{\mathrm{MAX}} \\
(\mathrm{cm})\end{array}$} & \multirow{2}{*}{$\begin{array}{c}S_{\mathrm{M}} \\
(\mathrm{cm})\end{array}$} & \multirow{2}{*}{$\begin{array}{l}\text { INT h } \\
(\mathrm{cm})\end{array}$} \\
\hline Year & GPS week & & & \\
\hline 1997 & (932-934) & 0.6 & 0.4 & 3.1 \\
\hline 1998 & $(959-960)$ & 1.0 & 0.7 & 5.4 \\
\hline
\end{tabular}

confidence interval on the height estimates is about $4 \mathrm{~cm}$.

To account for possible residual systematic effects on coordinate differences, generally due to ephemeris errors (Bányai, 1991; Crespi et al., 1993), four parameters (scale and rotations) between the two coordinate sets were estimated. Thanks to the very good satellite ephemerides quality provided by CODE, no significant scale and rotation parameters were found in the comparison.

The observed coordinate differences between the two coordinate sets were submitted to the significance analysis by DENETGPS (Crespi, 1996). This software performs a test based on the Fisher variate with the aim of separating the sites into two groups, those whose coordinates are significantly changed with respect to the error ellipsoids from those whose coordinates are not changed. DENETGPS was successfully tested in suitably designed experiments by producing known displacements on one site of a GPS network (Crespi and Riguzzi, 1998; Betti et al., 1999). The software allows to perform the analysis at tri-dimensional, two-dimensional (planar) or mono-dimensional (vertical) level. In our case, we chose to analyze separately the planar from the vertical components (the estimation of the tropospheric delays degrades the precision of the height estimates) to better focus our study on the planar component.

Table II shows the results of the analysis at $5 \%$ significance level in which the experimental Fisher values $F_{e}$ are compared with the threshold value $F_{t}$; sites with $F_{e}>F_{t}$ exhibit significant coordinate differences.

The analysis performed on the vertical component does not show any significant height difference. On the contrary, the analysis on the planar component shows how all the coordinate differences pertaining to the 7 sites located on the Sinai peninsula are significant, while the remaining 5 sites display small differences within the errors.

This result is very important because it shows how the whole Sinai peninsula has a rather uniform behaviour with the highest detected motion of the whole analyzed area. This fact is particularly enhanced when we compute the displacement vectors, taking into account the results of 
Table II. Sinai network. Deformation analysis (5\% significance level).

\begin{tabular}{ccc}
\hline Site & Planar & UP \\
& $F_{t}=3.08$ & $F_{t}=3.93$ \\
\hline GARB & 1.48 & 0.01 \\
GEMS & 0.25 & 0.03 \\
HURG & 0.97 & 0.04 \\
SHAM & $\mathbf{6 . 6 9}$ & 0.03 \\
KENS & $\mathbf{4 . 4 2}$ & 0.00 \\
TOUR & $\mathbf{1 6 . 6 9}$ & 0.10 \\
DERB & $\mathbf{6 . 7 5}$ & 0.39 \\
CATH & $\mathbf{8 . 1 5}$ & 0.01 \\
NABQ & $\mathbf{5 . 2 2}$ & 0.00 \\
ZEIT & 0.12 & 0.06 \\
DAHA & $\mathbf{6 . 7 7}$ & 0.17 \\
ELAT & 0.58 & 0.70 \\
\hline
\end{tabular}

Table III. Sinai network. 2D displacements, azimuth and r.m.s.

\begin{tabular}{ccc}
\hline \hline Site & $\begin{array}{c}\text { VT2D } \pm \text { r.m.s. } \\
(\mathrm{cm})\end{array}$ & $\begin{array}{c}\text { Azimuth } \\
(\mathrm{deg})\end{array}$ \\
\hline GARB & - & - \\
GEMS & $0.6 \pm 0.6$ & 167 \\
HURG & $0.9 \pm 0.8$ & 179 \\
SHAM & $\mathbf{1 . 6} \pm \mathbf{0 . 7}$ & $\mathbf{- 1 5 8}$ \\
KENS & $\mathbf{1 . 0} \pm \mathbf{0 . 6}$ & $\mathbf{- 1 4 3}$ \\
TOUR & $\mathbf{1 . 8} \pm \mathbf{0 . 6}$ & $\mathbf{- 1 7 9}$ \\
DERB & $\mathbf{1 . 6} \pm \mathbf{0 . 6}$ & $\mathbf{- 1 5 4}$ \\
CATH & $\mathbf{1 . 7} \pm \mathbf{0 . 7}$ & $\mathbf{- 1 6 5}$ \\
NABQ & $\mathbf{1 . 5} \pm \mathbf{0 . 7}$ & $\mathbf{- 1 3 4}$ \\
ZEIT & $0.4 \pm 0.6$ & 172 \\
DAHA & $\mathbf{1 . 6} \pm \mathbf{0 . 7}$ & $\mathbf{- 1 2 1}$ \\
ELAT & $0.7 \pm 0.6$ & -173 \\
\hline
\end{tabular}

the deformation analysis. The $2 \mathrm{D}$ vector displacements, their azimuths and the corresponding error ellipses on the local tangent plane at $95 \%$ confidence level were computed with respect to GARB (table III) and reported in fig. 2.

Although the more general representations of vector displacements is to compute them with respect to the datum baricentrum, i.e. the baricentrum of the stable sites (Brunner et al., 1981; Koch, 1984), the choice to compute vectors with respect to one site is still correct (Teunissen, 1985) and justified by the fact that GARB never showed significant displacement; from a geophysical point of view the meaning is to refer displacements to the stable Egyptian shore of the Red Sea.

The displacement uniformity exhibited by the Sinai peninsula (within the errors) supports the idea that the Sinai area behaves like a subplate subjected to the action of the African and the Arabian plates. Hence, hypothesizing that it moves like a rigid block, we can try to evaluate approximately its mean motion with respect to GARB. The mean displacement of the 7 Sinai sites is about $1.5 \pm 0.6 \mathrm{~cm}$ with a mean azimuth of $-152^{\circ}$ (or $208^{\circ}$ ), if computed over the period of six months; consequently, an approximate estimate of the mean velocity, obtained by propagating the mean displacement over one year, is $3.0 \pm 1.2 \mathrm{~cm} / \mathrm{yr}$. Note that velocity seems to sharply decrease toward ELAT $(1.4 \pm 1.2 \mathrm{~cm} / \mathrm{yr})$ at less than $50 \%$ of its mean value.

\section{Discussion}

In this study a rigorous analysis of GPS data from a network located across the Gulf of Suez up to the inner Gulf of Aqaba was carried out. The network is composed of 12 sites, seven located on the Sinai peninsula, another four on the west shore of the Gulf of Suez and the last on the inner Gulf of Aqaba (ELAT, Israel). The deformation analysis shows significant planar displacements at all the sites of the Sinai peninsula. No globally significant displacements are exhibited by the remaining sites of the network, within the analyzed time span.

Concerning the three questions posed at the beginning of this paper, we think that this work makes an important contribution to understanding the kinematics of the Sinai peninsula, in spite of the limited time span analyzed.

First of all, our analysis gives evidences of significant coordinate differences of all the sites located on the Sinai peninsula in the time span of six months. Taking into account the errors, all 
the planar displacement vectors are similar (their magnitudes range from 1.0 to $1.8 \mathrm{~cm}$ and their azimuths from $-134^{\circ}$ to $-179^{\circ}$ ) evidencing a clear southwestern motion of the Sinai peninsula. A raw evaluation of the mean velocity of the Sinai sites gives about $3 \mathrm{~cm} / \mathrm{yr}$ with an azimuth of approximately $-152^{\circ}$. The trend displayed by the Sinai sites, resulting rather uniform and different from those located on the west shore of the Gulf of Suez, gives geodetic evidence of the sub-plate behaviour of the Sinai peninsula with respect to the African plate.

Although we believe that it is not possible to draw exhaustive geodynamical conclusions from two GPS surveys, we emphasize that our results are consistent with the left lateral motion of the Aqaba-Levant fault, as inferred from geological and seismological investigations. On the other hand, the lack of GPS data on the Arabian peninsula makes the discussion incomplete. No evidence of extension was detected for the Gulf of Suez, but rather unexpectedly, a contraction component seems to be found by the present work.

At present, it is not possible to answer to the last question because it requires more repeated analyses on longer time intervals. In the near future, it would be interesting to clarify whether the present motion can be considered aseismic or drifted by the residual strain release induced by the strong event of the November 22, 1995. This suspicion starts from the fact that the detected motion agrees well with the CMT focal mechanism solution given by Harvard University and the first study on the coseismic deformations induced by this earthquake (Kimata et al., 1997).

Finally, to add to our knowledge of the kinematics of this region it would be useful to have data from additional GPS sites located on the Arabian peninsula.

\section{Acknowledgements}

We wish to thank Prof. E. Boschi for supporting this work. We also acknowledge C. Noll product manager of the CDDIS, H. Habrich and $K$. Herzberger of IFAG and the GEODAF data archive of the Italian Space Agency (ASI) for providing GPS observations of the GPS permanent stations of Bahrain, Elat and Noto.
This study would not have been possible without the contribution made by many organizations and individuals in developing GPS tracking sites.

Special thanks are due to S. Pondrelli for helpful suggestions.

\section{REFERENCES}

BÁNYAI, L. (1991): Treatment rotation errors in the final adjustment of the GPS baseline components, Bull. Geod., 65 (2), 102-108.

Ben-Menahem, A., A. Nur and M. Vered (1976): Tectonics, seismicity and structure of the Afro-Eurasian junction - The breaking of an incoherent plate, Phys. Earth Planet. Inter., 12, 1-50.

BetTI, B., L. BIAGI, M. CRESPI and F. RiguzZI (1999): GPS sensitivity analysis applied to non-permanent GPS network, J. Geodesy, 73, 158-167.

BOUCHER, C. (1998): ITRF96 Solutions, http://lareg.ensg. ign.fr/ITRF/itrf96.html

BrunNer, F.K., R. COLEMAN and B. Hirsch (1981): A comparison of computation methods for crustal strains from geodetic measurements, Tectonophysics, 218, 237-264.

CRESPI, M. (1996): A software package for the adjustment and the analysis of GPS control networks, in Reports on Surveying and Geodesy, edited by M. UNGUENDOLI, University of Bologna (Edizioni Nautilus), 237-264.

CRESPI, M. and F. RIGUZZI (1998): Software available for analyzing GPS deformation, Eos, Trans., Am. Geophys. Un., 79, 22, 259 and Eos Electronic Supplement, http://www.agu.org/eos elec/98059e.html

CRESPI, M., B. MARANA, F. SANSÒ and D. SGuerso (1993): GPS leveling and the geoid, in Proceedings International Seminar on GPS in Central Europe, Penc, Hungary, 209-228.

DZIEWONSKI, A.M. and J.H. WoodHOUSE (1983): An experiment in systematic study of global seismicity; Centroid Moment Tensor solutions for 201 moderate and large earthquakes of 1981, J. Geophys. Res., 88, 3247-3271.

FAtTAH, A.K.A., H.M. HusSEIN, E.M. IBRAHIM and A.S.A. EL ATTA (1997): Fault plane solutions of the 1993 and 1995 Gulf of Aqaba earthquakes and their tectonic implications, Ann. Geofis., 40 (6), 1555-1564.

HARVARD CMT CATALOG: http://www.seismology.harvard.edu/CMTsearch.html

JACKSON, J.A., N.J. White, Z. GARFUNKEL and H. ANDERSON (1988): Relations between normal-fault geometry, tilting and vertical motions in extensional terrains: an example from the Southern Gulf of Suez, J. Struct. Geol., 10 (2), 155-170.

Kimata, F., A. Tealeb, H. Murakami, N. Furukawa, S. MAHMOUD, H. KHALIL, K.O. SAKR and A.M. HAMDY (1997): The Aqaba earthquake of November 22, 1995 and co-seismic deformation in Sinai peninsula, deduced from repeated GPS measurements, Acta Geod. Geophys. Hung., 32 (1-2), 53-71. 
KocH, K.R. (1984): Statistical tests for detecting crustal movements using Bayesian inference, NOAA Technical Report NOS NGS 29, National Geodetic Survey, Rockville, MD.

LE PICHON, X. and J.-M. GAULIER (1988): The rotation of Arabia and the Levant fault system, Tectonophysics, 153, 271-294.

Mahmoud, S., H. KoIvula, A.S. Mohamed, H. KHALIL and T.R. KEBEASY (1998): Monitoring recent movements in Sinai and around Gulf of Suez, Egypt, in The Ninth International Symposium on Recent Crustal Movements (CRCM '98), November 14-19, 1998, Cairo, Egypt.

Rothacher, M., G. Beutler, W. Gurtner, E. BrockMANN and L. MERVART (1996): Bernese GPS Software Version 4.0., edited by M. ROTHACHER and L. MERVART, University of Berne, Switzerland.

SAlamon, A., A. HOFSTETTER, Z. GARFUnKEL and H. RON
(1996): Seismicity of the Eastern Mediterranean region: perspective from the Sinai subplate, Tectonophysics, 263, 293-305.

STECKLER, M.S. (1985): Uplift and extension at the Gulf of Suez: indications of induced mantle convection, Nature, 317, 135-139.

Steckler, M.S., F. Berthelot, N. Liberis and X. LE PICHON (1988): Subsidence in the Gulf of Suez: implications for rifting and plate kinematics, Tectonophysics, 153, 249-270.

Teunissen, P.J. (1985): Zero order design: generalized inverses, adjustment, the datum problem and $S$-transformations, in Optimization and Design of Geodetic Networks, edited by E.W. GRAFAREND and F. SANSÒ (Springer-Verlag, Berlin), 11-55.

(received April 29, 1999; accepted June 25, 1999) 